\title{
Acne in Lomé, Togo: clinical aspects and quality of life of patients
}

\author{
Bayaki Saka ${ }^{*}$, Abla Séfako Akakpo1, Julienne Noude Téclessou², Abas Mouhari-Toure³, Garba Mahamadou', \\ Piham Gnossike ${ }^{1}$, Waguéna Gnassingbé ${ }^{1}$, Aurel Abilogoun-Chokki ${ }^{1}$, Adjalamotom Tawelessi ${ }^{1}$, \\ Koussake Kombaté ${ }^{2}$ and Palokinam Pitché
}

\begin{abstract}
Background: Acne is a chronic inflammatory condition affecting the pilosebaceous follicle that mainly affects adolescents and young adults. The aim of this study was to assess the quality of life (QOL) of patients with acne, and to determine the correlation between the QOL and the severity of acne, in Lomé (Togo).

Method: From July 2017 to February 2018, we conducted a study in three dermatology departments of Lomé. The clinical evaluation of acne and assessment of the QOL were done using the ECLA (Echelle de Cotation des Lésions d'acné) and CADI (Cardiff Acne Disability Index) scores respectively.

Results: We enrolled 300 patients aged 12 to 52 years; $71.3 \%$ of whom were female. The face was affected by acne in $100 \%$ of cases and papulopustular acne was the most common clinical form (66.7\%). Acne was mild to moderate in 162 patients (54\%) and severe in 138 (46\%). Impairment was observed in all patients' QOL (scores ranged from 1 to 14 points). There was a positive correlation between severity of acne and QOL impairment in the patients $(r=0.21 ; p=0.0002)$. We also found a positive correlation between overall CADI score and factors F1 and F3 of the ECLA scale: the severity of facial acne $(r=0.15 ; p=0.0073)$ and the presence of scars $(r=0.21 ; p=0.0002)$. In contrast, the global ECLA score was significantly correlated with items 2,3 , and 5 of the CADI questionnaire: the patient's relationship $(r=0.13 ; p=0.0241)$, avoidance behaviors $(r=0.21 ; p=0.0002)$ and perception of acne $(r=0.16 ; p=0.0067)$.
\end{abstract}

Conclusion: Acne negatively impacts the QOL of patients. The severity of acne has an impact on the patient's relationships, avoidance behaviors and perception of the acne.

Keywords: Acne, Quality of life (QOL), Lomé (Togo)

\section{Background}

Acne is a chronic inflammatory condition affecting the pilosebaceous follicle, involving four elements: the sebaceous gland, the follicular canal epithelium, a bacterium called Propionibacterium acnes and innate cutaneous immunity $[1,2]$. Acne is a benign condition that mainly affects adolescents and young adults, whose prevalence varies according to the authors between 80 and 95\% [3-7]. Despite this benign nature, many studies have shown that it has a negative impact on the quality of life (QOL) of patients [8-11], but so far, no such study has been conducted in Togo. The only study on acne published in Togo described the clinical features in patients using skin-bleaching products [12]. The

\footnotetext{
* Correspondence: barthelemysaka@yahoo.fr

${ }^{1}$ Dermatology Unit, Sylvanus Olympio Teaching Hospital, University of Lomé, B.P, 30785 Lomé, Togo

Full list of author information is available at the end of the article
}

aim of our study was to assess the QOL of patients with acne, and to determine the correlation between the QOL and the severity of acne in Togo.

\section{Method}

We conducted a descriptive cross-sectional study between July 2017 and February 2018, in three dermatology units in Lomé (Togo). We included, after obtaining their consent, all patients diagnosed with acne by a dermatologist in these centers during the study period. Patients were recruited during the dermatology consultations. All the patients included in the study were visited for their acne for the first time and they were not already on treatment. The socio-demographic characteristics (age, sex, profession) were collected by a dermatologist during the interview and the physical examination. The dermatologist specified on the patient's record the type of lesions, their location and 
the clinical form. The clinical evaluation of acne and QOL was performed with the ECLA (Echelle de Cotation des lésions d'acné) scale [13] (Additional file 1) and CADI (Cardiff Acne Disability Index) scale respectively [14] (Additional file 2). The two scales both French were validated in Togo par the Togolese Dermatology Society. The ECLA scale is composed of 3 factors (F1, F2 and F3) which respectively evaluate the type and intensity of facial acne, the extension and intensity of acne on regions other than the face and the presence of scars. The CADI questionnaire contained 5 items that respectively evaluate the emotions of the patient, his social relations, the avoidance behaviors, feelings of anxiety and the overall perception of acne. After each consultation, patients included in the study were asked to complete these two questionnaires.

\section{Calculation and interpretation of scores}

The total ECLA score, obtained from the sum of the F1, F2, and F3 scores, ranged from 0 to 36. An ECLA score of 12 or less represented mild to moderate acne, a score greater than 12 represented severe acne. To establish the CADI score, the answers were graded as follows: (a) 3 points, (b) 2 points, (c) 1 point and (d) 0 point. The score calculated by adding the number of points for each question varied between 0 and 15 . The interpretation was as follows: $0=$ no change in QOL; 1 to $5=$ slight impairment of QOL; 6 to $10=$ moderate impairment of QOL; 11 to 15 $=$ severe impairment of QOL.

\section{Data analysis}

The data were entered using the software Epidata version 3.1. Before being analyzed, data had been verified and cleared. The statistical analyses were performed with the software R Studio version 3.3.4. The analysis initially enabled the description of the study population. The results were expressed in terms of relative and absolute frequency for the qualitative variables; mean and standard deviation for the quantitative variables. Then, for the quantitative variables, we used the Pearson correlation test or the Student's t-test (two-way variables) to analyze the variability of the dependent variables according to the characteristics of the study population. For qualitative variables, we used the Analysis of variance method (ANOVA) for the variables with more than two modalities. The threshold of significance was set at 0.05 .

\section{Results}

During the study period, 300 patients with acne were included. Their mean age was $23.7 \pm 5.7$ years (range: 12 to 52 years) and the sex-ratio (Male/Female) was 0.4. More than two-thirds $(69.3 \%)$ of patients were less than 25 years old and the students were mostly represented (58.7\%). The acne was located on the face in $100 \%$ of cases, alone or in combination with other locations. The most common acne lesions were papules (97.3\%); papulopustular acne was the most common clinical form (66.7\%) (Table 1). The mean ECLA severity score was $12.3 \pm 5.0$ (range: 2 to 28). Acne was mild to moderate in 162 patients (54.0\%) and severe in 138 (46.0\%). The mean CADI score was $7.3 \pm 3.0$ (range: 1 to 14). Impaired QOL was observed in all patients. It was considered mild in 85 patients, moderate in 166 and severe in 49. There was a positive correlation between the scores of the two scales ECLA and CADI $(r=0.21 ; p=0.0002)$ (Fig. 1). A positive correlation was equally found between the overall CADI score and factors F1 and F3 of the ECLA scale (Table 2), as well as between the ECLA score and items 2, 3, and 5 of the CADI questionnaire (Table 3).

\section{Discussion}

The results of our study showed that i) $46 \%$ of patients had severe acne; ii) QOL of all patients was impaired; iii) There was a positive and significant correlation between severity of acne and impairment of patients' QOL.

We found that the mean age of our patients was $23 \pm$ 5.7 years, which was slightly less than those reported by other studies carried out in hospitals: 25 years in

Table 1 Patient characteristics

\begin{tabular}{lll}
\hline Patient characteristics & Number & Percent \\
\hline Type of lesions & 292 & \\
Papules & 277 & 97.3 \\
Hyperseborrhoea & 272 & 92.3 \\
Blackheads & 249 & 90.7 \\
Hyperpigmented macules & 217 & 83.0 \\
Pustules & 177 & 72.3 \\
Excoriation & 120 & 59.0 \\
Crusty stitches & 104 & 40.0 \\
Punctuate depressions & 95 & 34.7 \\
Nodules & 83 & 31.7 \\
Cysts & 33 & 27.7 \\
Atrophic scars & 23 & 11.0 \\
Hypertrophic scars & & 7.7 \\
Location of lesions & 300 & \\
Face & 190 & 100 \\
Back & 140 & 63,3 \\
Neck & 136 & 46,6 \\
Chest & 60 & 45,3 \\
Arms & 58,3 \\
Clinical forms of acne & 7500 \\
Rapulo pustular acne & & \\
Nodular acne & & 11,7 \\
Pigmented acne & & \\
\hline
\end{tabular}




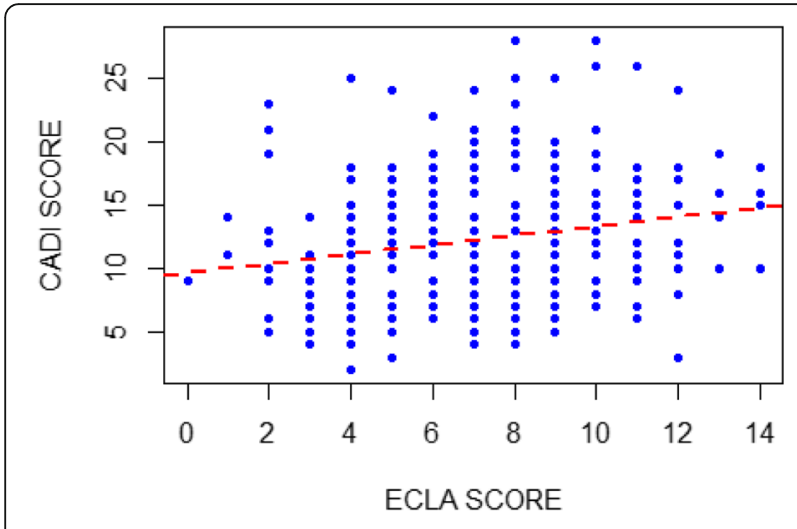

Fig. 1 Correlation between ECLA and CADI scores $(r=0.21 ; p=0.0002)$

Cameroon [8], 25.6 years in Senegal [15] and 23.8 years in Morocco [16]. This relatively higher age reported in these studies could be due to the fact that in Togo, acne is neglected in adolescents since parents hardly seek medical care because it is considered as a normal phenomenon. In the study conducted in Burkina Faso, [17], the mean age of patients with acne was 19.5 years old, since the study was carried out in schools. We noted a female predominance like in the study of Kouotou et al. [8]. This is explained by the fact that women are more likely to seek medical care than men for any apparent and unsightly illness (100\% of patients had facial lesions).

In our study, papulopustular acne was the most represented clinical form as in other series $[8,15]$. We found 7 cases $(2.3 \%)$ of acne pigmentosa, a form peculiar to black or pigmented skin. The frequency of excoriations (59\%) could be related to self-injury likely triggered by obsessive disorders that acne causes.

We also found that the proportion of severe acne is high (46\%) with a mean ECLA score of $12.3 \pm 5$. Slightly lower average ECLA scores were reported by Kouotou et al. in Cameroon (11 \pm 4.5$)$ [8] and Dreno et al. in France $(8.26 \pm 3.32)$ [9]. The proportion of severe forms found by Kouotou et al. [8] was also high (30.4\%). On the other hand, the study conducted by Ouedraogo et al. [17] in Burkina Faso reported $4.75 \%$ of severe acne. This difference could be explained by the distinct settings of both studies, Ouedraogo et al. [17] having done theirs in schools.

Table 2 Correlation between CADI score and the three factors of the ECLA scale

\begin{tabular}{llll}
\hline & ECLA & & \\
\cline { 2 - 4 } & Factor 1 & Factor 2 & Factor 3 \\
\hline CADI score $(r)$ & 0.15 & 0.11 & 0.21 \\
p-value & 0.0073 & 0.0606 & 0.0002 \\
\hline
\end{tabular}

Table 3 Correlation between global ECLA score and the five items of the CADI score

\begin{tabular}{lcllll}
\hline & CADI & & & & \\
\cline { 2 - 6 } & Item1 & Item2 & Item3 & Item4 & Item5 \\
\hline ECLA score $(r)$ & 0.05 & 0.13 & 0.21 & 0.08 & 0.16 \\
p-value & 0.35 & 0.0241 & 0.0002 & 0.1640 & 0.0067 \\
\hline
\end{tabular}

In our study, QOL impairment was observed in all patients. Thus, even minimal acne can have a negative impact on QOL. The overall mean CADI score was $7.3 \pm$ 3.0. This result is close to those of other studies that found mean values of $6.3 \pm 3.4$ [8], $4.86 \pm 3.11$ [18] and $4.8 \pm 2.9$ [19]. Many studies using other scales have also demonstrated QOL impairment in all patients $[20,21]$. This proves that acne negatively affects the patient's QOL, self-esteem and mood because of its apparent and unsightly nature.

In our study, the correlation between global ECLA and overall CADI was positive, suggesting that the more acne is severe, the more it will alter patients' QOL. Apart from Dréno et al. [9], several studies [8, 17] found that there was a positive correlation between severity of acne and QOL impairment. These differences may be because these studies focused on different categories of populations. Other studies using different tools have also shown a relationship between the severity of acne and the QOL of the patients $[10,21]$. Moreover, as in the study of Dréno et al. [9], we found a positive correlation between the CADI score and factors F1 and F3, meaning that the type and intensity of facial acne and the presence of scars influence QOL impairment of patients. There was no correlation between the CADI score and the F2 factor, (the location of acne lesions on regions other than the face) because this other location is hidden. However, Kouotou et al. [8] found a positive correlation between the CADI score and all three factors on the ECLA scale.

In contrast, there was a positive correlation between the severity of acne and patient relations $(p=0.0241)$, avoidance behaviors $(p=0.0002)$, and overall perception of acne $(p=0.0067)$. On the other hand, the severity of acne did not affect either the mood or the feelings of anxiety triggered by acne. This correlation between the ECLA score and the 5 items of CADI questionnaire was very different from one study to another $[8,9,17]$. While Kouotou et al. [8] found a positive correlation between ECLA and the 5 items, Ouedraogo et al. found a correlation between ECLA and items 2 and 4 [17]; while Dreno et al. [9] reported a correlation between ECLA and item 5 . Of these four studies, correlations between ECLA and items 2 and 5 were mentioned three times, while correlations between ECLA and item 4 were mentioned twice. These four studies showed that the severity 
of acne is more correlated with the overall perception of acne, avoidance behaviors and feelings of anxiety triggered by acne.

\section{Limitations}

The main limitation of this study was that it was conduct in hospital setting. Indeed, the detrimental effects of acne on a patient's quality of life (relations, perception of acne) must have prompted a consultation. Secondly, no control group was used in this study. The use of a control group would have made it possible to see if the QOL impairment in the patient's was really related to the presence of acne.

\section{Conclusion}

Acne had a negative impact on the QOL of patients who suffer from it. The type and intensity of facial acne, and the presence of scars impacted the patient's overall QOL. In addition, the overall severity of acne has an impact on the patient's relationships, avoidance behaviors and overall perception of acne.

\section{Additional files}

Additional file 1: Presentation of the ECLA scale. (DOCX $18 \mathrm{~kb}$ )

Additional file 2: Cardiff Acne Disability Index (CADI). (DOCX $15 \mathrm{~kb}$ )

\section{Abbreviations}

ANOVA: Analysis of variance method; CADI: Cardiff acne disability index; ECLA: Echelle de Cotation des Lésions d'Acné; QOL: Quality of life

\section{Acknowledgements}

We would like to thank Dr. Dadja E. LANDOH, Dr. Sandra TATAH AYUK, Medical doctors, and Stephanie PARENT, BSC, MPH, for reviewing and copyediting the manuscript.

\section{Availability of data and materials}

Extracted data are with the authors and available for sharing on request.

\section{Authors' contributions}

$B S, A S A, J N T, A M, G M, P G, W G, A A$ and $A T$ : participated in data collection and wrote the manuscript. KK and PP: have revised and finalized the manuscript. All the authors had read and approved the final manuscript to be submitted for publication.

\section{Ethics approval and consent to participate}

This study was approved by the Department of Dermatology of the Sylvanus Olympio Teaching Hospital, University of Lomé. We obtained the approval from the participants. The participants gave their consent, after the verbal explanation was delivered by the clinicians of the participating hospitals. The survey was anonymous and confidential.

\section{Consent for publication}

The Department of Dermatology of Sylvanus Olympio Teaching Hospital, University of Lomé authorized the publication of this manuscript.

\section{Competing interest}

The authors declare that they have no competing interests.

\section{Author details}

'Dermatology Unit, Sylvanus Olympio Teaching Hospital, University of Lomé, B.P, 30785 Lomé, Togo. ${ }^{2}$ Dermatology Unit, Campus Teaching Hospital, University of Lomé, Lomé, Togo. ${ }^{3}$ Dermatology Unit, Kara Teaching Hospital, University of Kara, Kara, Togo.

Received: 17 May 2018 Accepted: 15 August 2018

Published online: 22 August 2018

\section{References}

1. Pawin H, Beylot C, Chivot M, Faure M, Poli F, Revuz J, et al. Physiopathology of acne vulgaris: recent data. new understanding of the treatments Eur J Dermatol. 2004:14:4-12.

2. Cunliffe WJ, Holland DB, Jeremy A. Comedone formation: etiology, clinical presentation, and treatment. Clin Dermatol. 2004:22:367-74.

3. Bhate K, Williams HC. Epidemiology of acne vulgaris. Br J Dermatol. 2013;168:474-85.

4. Williams HC, Dellavalle RP, Garner S. Acne vulgaris. Lancet. 2012;379:361-72.

5. Ghodsi SZ, Orawa H, Zouboulis CC. Prevalence, severity, and severity risk factors of acne in high school pupils: a communitybased study. J Invest Dermatol. 2009;129:2136-41

6. Nijsten T, Rombouts S, Lambert J. Acne is prevalent but use of its treatments is infrequent among adolescents from the general population. J Eur Acad Dermatol Venereol. 2007;21:163-8.

7. Yahya H. Acne vulgaris in Nigerian adolescents: prevalence, severity, beliefs, perceptions, and practices. Int J Dermatol. 2009:48:498-505.

8. Kouotou EA, Adegbidi H, Bene Belembe R, Sieleunou I, Nansseu JR, Kamga JP, et al. Acne in Cameroon: quality of life and psychiatric comorbidities. Ann Dermatol Venereol. 2016;143:601-6.

9. Dréno B, Alirezai M, Auffret N, Beylot C, Chivot M, Daniel F, et al. Clinical and psychological correlation in acne: use of the ECLA and CADI scales. Ann Dermatol Venereol. 2007;134:451-5.

10. Durai $P C$, Nair $D G$. Acne vulgaris and quality of life among young adults in South India. Indian J Dermatol. 2015;60:33-40.

11. Dun LK, O'Neill JL, Feldman SR. Acne in adolescents: quality of life, selfesteem, mood, and psychogical disorders. DermatolOnline J. 2011;17:1.

12. Kombaté K, Mouhari-Toure A, Saka B, Akakpo AS, Maboudou A, Pitché P, et al. Acne and skin bleaching in Lomé, Togo. Int J Dermatol. 2012;51(Suppl 1):27-9.

13. Dreno B, Bodokh I, Chivot M, Daniel F, Humbert P, Poli F, et al. La grille ECLA : un système de cotation de l'acné pour la pratique quotidienne du dermatologue. Ann Dermatol Venereol. 1999;126:136-41.

14. Motley RJ, Finlay AY. Practical use of a disability index in the routine management of acne. Clin Exp Dermat. 1992;17:1-3.

15. Kane A, Oumou Nang S, Cisse Digne A, Ly F, Ndiaye B. Epidemiologic, clinal, and therapeutic features of acne in Dakar. Senegal Int J Dermatol. 2007;466:36-8.

16. Mernissia F, Krich S, Mezianea M, Elfakirb S, Bouzidia H, Amraouia N, et al. Retentissement de l'acné sur la qualité de vie (échantillon d'une population marocaine). Ann Dematol Venereol. 2013:140:15.

17. Ouédraogo NA, Tapsoba GP, Ouédraogo MS, Ouédraogo-Kabré SK, Traoré F, Somé-Korsaga NN, et al. Acne and quaity of life of students in Ouagadougou. Int J Innov Appl Stud. 2017;20:187-94.

18. Cotterill JA, Cunliffe WJ. Suicide in dermatological patients. Br J Dermatol. 1997;137:246-50.

19. Zoung-Kanyi Bissek AC, Ntone EF, Mboua BJ, Nang A, Deh DG, Njamnshi AK, et al. Clinique et vécu de l'acné chez l'adulte. Health Sci Dis. 2008:9:47-50.

20. Yazici K, Baz K, Yazici AE, Köktürk A, Tot S, Demirseren D, et al. Diseasespecific quality of life is associated with anxiety and depression in patients with acne. J Eur Acad Dermatol Venereol. 2004;18:435-9.

21. Ghaderi R, Saadatioo A, Ghaderi F. Evaluating of life quality in patients with acne vulgaris using generic and specific questionnaires. Dermatol Res Pract. 2013:2013:1-7.

\section{Publisher's Note}

Springer Nature remains neutral with regard to jurisdictional claims in published maps and institutional affiliations. 